\title{
Phthalic acid esters in dissolved fractions of landfill leachates
}

\author{
Zhong Zheng ${ }^{a}$, Pin-Jing He ${ }^{a, *}$, Li-Ming Shao ${ }^{a}$, Duu-Jong Lee ${ }^{b}$ \\ astate Key Laboratory of Pollution Control and Resource Reuse, Tongji University, Shanghai 200092, PR China \\ bepartment of Chemical Engineering, National Taiwan University, Taipei 10617, Taiwan
}

\section{A R T I C L E I N F O}

Article history:

Received 13 December 2006

Received in revised form

18 June 2007

Accepted 19 June 2007

Available online 21 June 2007

Keywords:

Phthalic acid esters (PAEs)

Humic substances

Landfill leachate

Hydrogen bonding

Dissolved organic matter (DOM)

\begin{abstract}
A B S T R A C T
The distribution of phthalic acid esters (PAEs) (including diisobutylphthalate (DIBP), di- $n$ butylphthalate (DnBP) and bis(2-ethyl)hexylphthalate (DEHP)) in dissolved organic matter (DOM) fractions of leachates from sanitary or bioreactor landfills was evaluated. The leachate DOM was fractionated into humic acid (HA), fulvic acid (FA) and hydrophilic (HyI) fractions. Measurements showed that the PAEs were bound mostly to the HA fraction in leachate, regardless of their landfill age or the presence of leachate recirculation. The PAEs affinity for HA and FA differed considerably relative to the sorption coefficients reported for model compounds. Molecular weight of DOM correlated with PAEs partition in collected leachate samples fractions while aromaticity was a poor predictor. Based on the presence of phenolic, carboxyl or amide groups in DOM fractions, hydrogen bonding is likely to be involved in interactions between PAEs and leachate DOM. The peptide groups, particularly presented in HA fracion, might explain the strong affinity of PAEs for HA. The fluorescence excitation emission matrix contour plots showed that the HyI fractions shared certain similarities with humic substances in terms of molecular structure, which may be one reason why PAEs exhibited a clear sorption to the HyI fractions.
\end{abstract}

(c) 2007 Elsevier Ltd. All rights reserved.

\section{Introduction}

Municipal solid waste landfill represents a major reservoir for persistent hydrophobic organic contaminants (HOCs) which may seriously pollute the groundwater aquifer and surface water as they migrate away with leachate (Coors et al., 2003; Vilomet et al., 2003). It is widely recognized that the association between HOCs and large molecules, especially dissolved organic matter (DOM), significantly influences the apparent aqueous solubility of these HOCs and increases their mobility from solid matrix into aqueous environment (Bauer and Herrman, 1997; Kulshrestha et al., 2004; Öman and Rosqvist, 1999). This increase in mobility impacts the fate of these organic chemicals in water treatment processes (Müller et al., 2004; Walse et al., 2004) as well as their biological toxicity (Gigliotti et al., 2005).

Yamamoto et al. (2003) proposed that the interaction between steroid estrogens and DOM correlated with UV absorptivity and phenolic group concentration of the DOM, while the sorption coefficients of di- $n$-butylphthalate (DnBP) and DOM were dominated by nonspecific hydrophobic interactions estimated on the basis of the non-ring structure and hydrophobicity of DnBP. More extensive studies showed that model aromatic contaminants such as PAHs and PCBs were readily adsorbed on DOM with high aromaticity humic acids (HA) (Perminova et al., 1999). Akkanen et al. (2005) proposed that sorption of PAHs to DOM correlated with the lipophilicity of the compounds. Furthermore, the structural characteristics,

\footnotetext{
*Corresponding author. Tel./fax: +862165986104.

E-mail address: solidwaste@mail.tongji.edu.cn (P.-J. He). 0043-1354/\$- see front matter ๔ 2007 Elsevier Ltd. All rights reserved. doi:10.1016/j.watres.2007.06.040
} 
such as degree of aromaticity, polarity, molecular size and molecular configuration of DOM, correlated with its sorption capacities (Pedersen et al., 1999).

Phthalic acid esters (PAEs) are endocrine-disrupting compounds that can be highly concentrated in landfill leachate (Schwarzbauer et al., 2002). DOM-facilitated transport is an important transport mechanism for PAEs from solid waste (Bauer and Herrman, 1997). The DOM of leachate may be fractionated into HA, fulvic acids (FA) and hydrophilic (HyI) fractions (Chistensen et al., 1998; Ma et al., 2001). No information was found on the distributions of PAEs in different fractions of DOM in landfill leachate. The aims of this study were to (1) determine the distributions of PAEs in HA, FA and HyI fractions of landfill leachate; (2) assess the correlations between PAE binding affinity and the characteristics of soluble fractions (FA, HA and HyI) in landfill leachates.

\section{Materials and methods}

\subsection{Samples}

Leachates were collected from four municipal solid waste landfills in Shanghai City and Hangzhou City, China, named S-A, S-B, Z-A and Z-B, in February-March 2006. All four landfills were engineered with HDPE liners and leachate collection systems.

Samples S-A and S-B were gathered from two landfill sites in Shanghai City, both of which received municipal solid waste from Shanghai. Sample S-A was from a landfill site operated during 1999-2004, while sample S-B was from a landfill, the operation of which started about 1 year ago. Samples Z-A and Z-B were from landfill sites serving Hangzhou City, China, that had been operated for 2 years. The Z-B site is a full-scale $(50 \times 500 \mathrm{~m})$ bioreactor landfill. Sample Z-B comprised recirculated leachate from the bioreactor landfill.

At each sampling point, leachate was collected using a clean glass bottle and promptly transferred to $4 \mathrm{~L}$ dark glass flasks with aluminum caps. These leachates were then filtered using glass fiber filters of $0.7 \mu \mathrm{m}$ pores (GF/F, Waterman, Maidstone, UK) to separate solid phase and soluble phase of leachate. No PAEs were detected in filter papers. Table 1 lists the characteristics of these leachates. In this study, the materials passing through $0.7 \mu \mathrm{m}$ glass fiber filters are considered as "soluble".

Table 1 - Characteristics of leachate samples

\begin{tabular}{lcccc}
\hline Samples & S-A & S-B & Z-A & Z-B \\
\hline COD (mg/L) & 5380 & 2800 & 8100 & 4690 \\
BOD (mg/L) & 1590 & 440 & 2670 & 464 \\
$\mathrm{PH}$ & 8.1 & 6.9 & 7.5 & 8.2 \\
$\mathrm{NH}_{3}-\mathrm{N}(\mathrm{mg} / \mathrm{L})$ & 600 & 860 & 1390 & 1760 \\
TP $(\mathrm{mg} / \mathrm{L})$ & 0.83 & 3.23 & 34.5 & 17.4 \\
& & & & \\
\hline
\end{tabular}

\subsection{Reagents and resins}

Three PAEs, diisobutylphthalate (DIBP), DnBP and di(2-ethylhexyl)phthalate (DEHP) were the target compounds. The PAEs mixed standard (including DnBP and DEHP), and the DIBP standard were obtained from Sigma-Aldrich (St. Louis, USA). Standard solutions of PAEs were prepared using dichloromethane as the solvent for calibration use.

The XAD-2 resin and XAD-8 resin (Supelco, Bellefonte, USA) were, respectively, extracted for $24 \mathrm{~h}$ via Soxhlet extraction sequentially in methanol, dichloromethane and methanol, and were soaked in distilled water before use. All solvents used were ABSOLV pure, purchased from Tedia (Fairfield, USA).

All glassware was rinsed sequentially with acetone, hexane and dichloromethane and dried at $400{ }^{\circ} \mathrm{C}$. Moreover, blank levels of PAE were monitored during sample preparation and considered in the corresponding calculations.

\subsection{Isolation and characterization of DOM}

Speciation of HA, FA and HyI fractions in leachate samples was performed using the method described by He et al. (2006). For quality control in PAEs analysis, $0.7 \mu \mathrm{m}$ glass filters (GF/F Waterman, Maidstone, UK) were used. This setup was used to fractionate the DOM in leachate into HA, FA and HyI fractions. A TOC/TN analyzer (multi N/C 3000, Analytik Jena AG, Jena, Germany) was used to measure the dissolved organic carbon (DOC) of the samples following fractionating. The weightaverage molecular weights of DOM fractions were determined by gel permeation chromatography using pure water eluent (LC-10ADVP, Shimadzu, Kyoto, Japan). UV analysis was performed using a spectrophotometer (Precision \& Scientific Instrument Co., Shanghai, China). The specific ultraviolet absorbance at wavelength $254 \mathrm{~nm}\left(\mathrm{SUVA}_{254}\right)$ was defined as UV absorbance at $254 \mathrm{~nm}$ divided by DOC content (Li et al., 1998).

Fluorescence excitation-emission matrix (EEM) spectra were recorded by a fluorescence spectrophotometer (F-4500, Hitachi, Tokyo, Japan) with a xenon lamp as the excitation source. Excitation and emission slit widths of $10 \mathrm{~nm}$ were used. This experiment collected EEM spectra with subsequent scanning emission spectra from 250 to $700 \mathrm{~nm}$ at $5 \mathrm{~nm}$ increments by varying the excitation wavelength from 200 to $450 \mathrm{~nm}$ at $4 \mathrm{~nm}$ increments. A low solution concentration was used to reduce primary and secondary inner filtering effects.

Fourier-transform infrared (FTIR) spectroscopy (EQUINOX 55, Bruker, Karlsruhe, Germany) was scanned from 4000 to $400 \mathrm{~cm}^{-1}$. The spectra were gathered on freeze-dried samples of $\mathrm{HA}, \mathrm{FA}$ and $\mathrm{HyI}$ as $\mathrm{KBr}$ pellets.

\subsection{Analysis of PAEs}

The extraction procedure was based on the method of Nascimento Filho et al. (2003). The aqueous phase obtained from the fractionating was passed through a glass column $(10 \mathrm{~cm} \times 10 \mathrm{~mm}$ ID), pre-treated by packing with $2 \mathrm{~g}$ of Amberlite XAD-2. The adsorbed material was eluted using $5 \mathrm{~mL}$ of a solution of methanol in acetone $(30 \% \mathrm{v} / \mathrm{v})$. 
The extract was then cleaned up using Florisil column (Supelco, Bellefonte, USA). Biphenyl $(10 \mu \mathrm{g})$ was added as the GC internal standard. This procedure was performed in triplicate.

A GC-FID system (Focus GC, Thermo Electron, San Jose, USA) was used to quantify the PAEs. The capillary column was a DM$5(30 \mathrm{~m}, 0.32 \mathrm{~mm}$ ID, $0.25 \mu \mathrm{m}$ film, Dikma, USA) and injection was splitless for $0.8 \mathrm{~min}$. The gas chromatograph was temperature programmed from 70 to $220^{\circ} \mathrm{C}$ at a rate of $20^{\circ} \mathrm{C} / \mathrm{min}$ with an initial hold time of $1 \mathrm{~min}$, and further heated to $270^{\circ} \mathrm{C}$ at $5^{\circ} \mathrm{C} / \mathrm{min}$. Nitrogen was used as the carrier gas with a flow rate of $1.5 \mathrm{ml} / \mathrm{min}$. The base temperature of the FID was $270^{\circ} \mathrm{C}$.

\section{Results and discussion}

\subsection{DOM contents}

Table 2 lists the DOC ratio of the HA, FA and HyI fractions of the four leachates and Table 3 lists their weight-average

Table 2 - DOC ratio (\%) of HA, FA and HyI fractions in leachate samples

\begin{tabular}{lccc}
\hline Samples & HA & FA & HyI \\
\hline S-A & 24.6 & 36.3 & 39.1 \\
S-B & 14.9 & 37.3 & 47.8 \\
Z-A & 12.0 & 36.4 & 51.6 \\
Z-B & 7.8 & 34.0 & 58.2 \\
\hline
\end{tabular}

Table 3 - Weight-average molecular weight of HA, FA and HyI fractions in leachate samples

\begin{tabular}{lccc}
\hline Samples & \multicolumn{3}{c}{ Weight-average molecular weight, $10^{3} \mathrm{Da}$} \\
\cline { 2 - 4 } & HA & FA & HyI \\
\hline S-A & 130975 & 1576 & 35 \\
S-B & 7486 & 1277 & 69 \\
Z-A & 1466 & 783 & 29 \\
Z-B & 1169 & 992 & 23 \\
& & & \\
\hline
\end{tabular}

molecular weights (MWs). Based on DOC analyses, the HyI fraction was the predominant fraction (>39\%) in each leachate sample. The S-A sample came from an old landfill and had a high HA content with a high weight-average MW. Owing to leachate recirculation, sample Z-B had low HA content and weight-average MWs, correlating with the findings of $\mathrm{He}$ et al. (2006). The weight-average MW for HA and FA exceeded those for HyI.

Regarding the IR spectra of HA and FA fractions (Fig. 1), the absorbance bands of the methyl and methylene groups at 2929 and $2957 \mathrm{~cm}^{-1}$ indicate the presence of aliphatic chains and weak humification (Polak et al., 2005). Moreover, the FA fraction displayed IR absorbance bands indicative of carboxylic groups (stretching vibrations of $\mathrm{C}=\mathrm{O}$ at $1714 \mathrm{~cm}^{-1}$, of $\mathrm{C}-\mathrm{O}$ at 1401 and $1233 \mathrm{~cm}^{-1}$, and of $\mathrm{O}-\mathrm{H}$ at around $3428-3440 \mathrm{~cm}^{-1}$ ), while HA displayed IR bands of carboxylic and peptide groups (stretching vibrations of -CO-NH- at 1646 and $1546 \mathrm{~cm}^{-1}$ ). The bands of lignin groups were observed on the HA spectra at 1505, 1451, 1401, and $1383 \mathrm{~cm}^{-1}$ (Lumsdon and Fraser, 2005). HyI had intensive absorbance bands of carboxylate groups at 1646 and $1401 \mathrm{~cm}^{-1}$ and of hydroxyl groups at $3440 \mathrm{~cm}^{-1}$.

\subsection{Partitioning of PAEs in DOM fractions}

Most PAEs in the leachate sample were soluble (Fig. 2). Hence the PAEs may largely bind with the dissolved molecules in the leachate.

The distribution of PAEs in DOM fractions in the leachate ( $D_{\text {PAEs }}, \mu g / \mathrm{mg}$ ) was calculated as the corresponding PAE concentration $(\mu \mathrm{g} / \mathrm{L})$ normalized by the DOM concentration (mg C/L). Fig. 3 illustrates the $D_{\text {PAEs }}$ of the three DOM fractions in the four leachate samples.

The $D_{\text {PAEs }}$ for HA fraction generally exceeded those for FA and HyI in all the samples studied, regardless of their landfills age and the presence of leachate recirculation. Additionally, the $D_{\text {PAEs }}$ for FA fraction were generally no less than those of HyI. The recirculated leachate could leach out more PAEs in lab-scale bioreactor landfill if it had higher DOC content (Bauer and Herrman, 1997). Our results indicated that the leached PAEs may be associated with HA fraction in leachate.
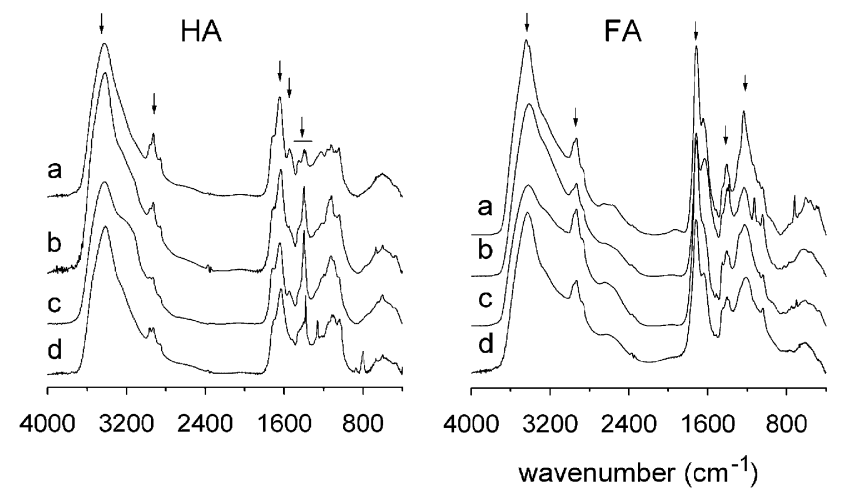

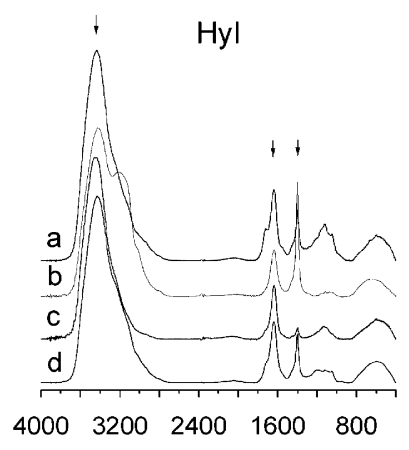

$400032002400 \quad 1600 \quad 800$

Fig. 1 - Fourier-transform infrared (FT-IR) spectra in the range $4000-400 \mathrm{~cm}^{-1}$ for the freeze-dried HA, FA and HyI fractions from leachates S-A (a), S-B (b), Z-A (c) and Z-B (d). 
Since the full-scale bioreactor landfill yielded a leachate (Z-B) with lower HA fractions than its full-scale sanitary counterpart (Z-A) receiving the same Municipal Solid Waste, the potential to leach PAEs from the former may be lower than for the latter.

The nonspecific hydrophobic interaction was considered to yield affinity between HOCs and humic substances (Yamamoto et al., 2003). The sorption coefficients $\left(K_{O C}\right)$ of PAEs on HA and FA in model compounds obtained from river sediments were found to be close $\left(10^{4.9}\right.$ in Suwannee River

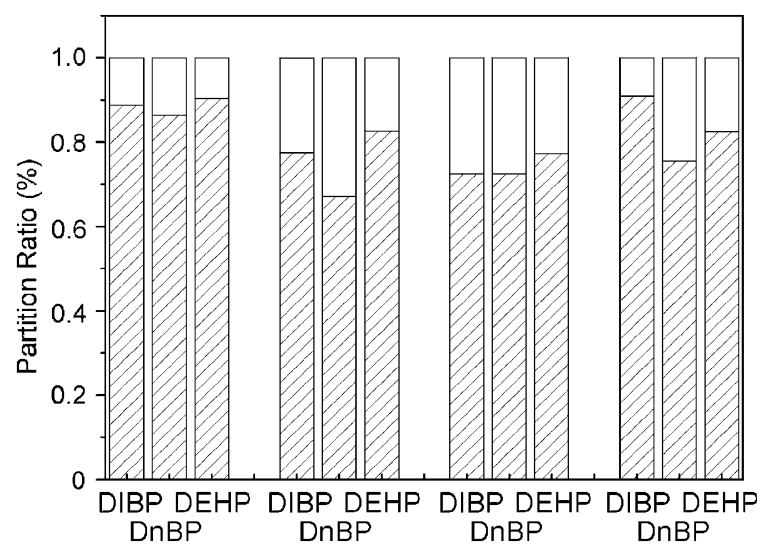

Fig. 2 - Partition of PAEs between sediments $(\square)$ and filtrate (미) of $0.7 \mu \mathrm{m}$ filter.

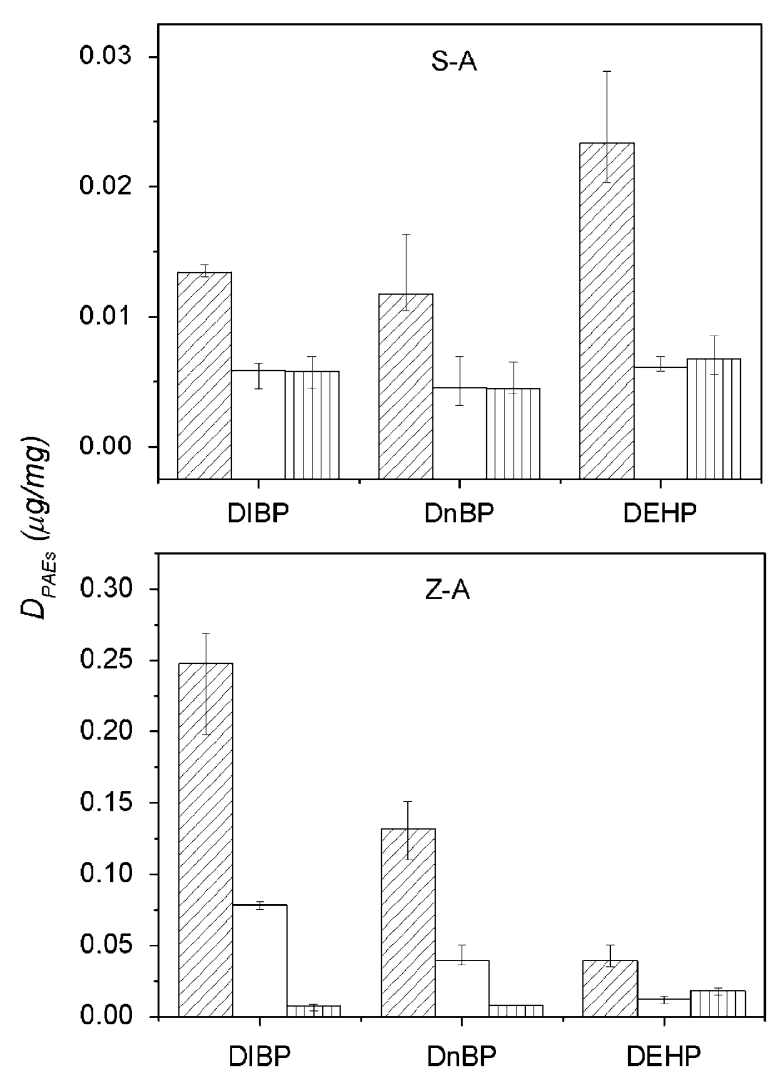

Fig. 3 - Distribution of PAEs ( $D_{\text {PAEs }} \mu \mathrm{g} / \mathrm{mg}$ ) in HA (䀑), FA ( $\square$ ) and HyI (四) fractions of leachate DOM.

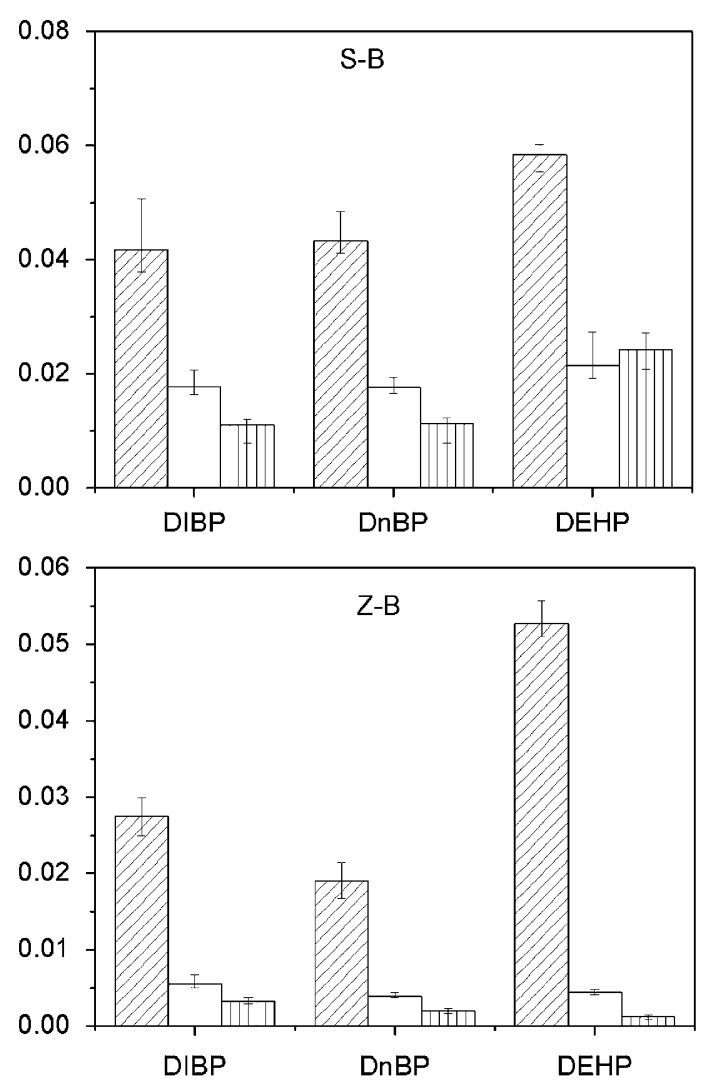

HA and $10^{4.85}$ in Suwannee River FA). However, the $D_{\text {PAEs }}$ of PAEs for HA and FA in leachate samples differed considerably (Fig. 3). Mackintosh et al. (2006) recommended that the sorption of PAEs on the particular matter led to substantially higher PAE adsorption than the one predicted by $\mathrm{K}_{\mathrm{OW}}$-based sorption models. However, these authors did not propose any mechanisms corresponding to the noted discrepancies.

\subsection{Relation between PAE distributions and molecular structure of DOM fractions}

In polluted groundwater, elemental compositions ( $\mathrm{C}, \mathrm{H}$ and $\mathrm{O}$ ) of HA, FA and HyI fractions have been found to be similar (Chistensen et al., 1998). In our study, the $D_{\text {PAEs }}$ reduced exponentially with $\mathrm{SUVA}_{254}$, which is in relation with the aromatic extent of the samples (Fig. 4). These data indicated that the aromaticity of adsorbents (HA, FA and HyI) was negatively correlated with PAE partition in the collected leachate samples. This observation contrasts with the commonly accepted concept that molecules with numerous aromatic groups tend to adsorb more PAEs.

On the other hand, the $D_{\text {PAEs }}$ of PAEs increased exponentially with increasing MWs of the DOM fractions (Fig. 5). The size of adsorbents (HA, FA and HyI) was more closely correlated with the PAE partition in the collected leachate samples than with their aromaticity.

Since the ester groups of PAEs have low $\mathrm{H}$-donor capability and polarizability, the PAEs were considered to have less affinity to DOM than the organic cations (Yamamoto et al., 


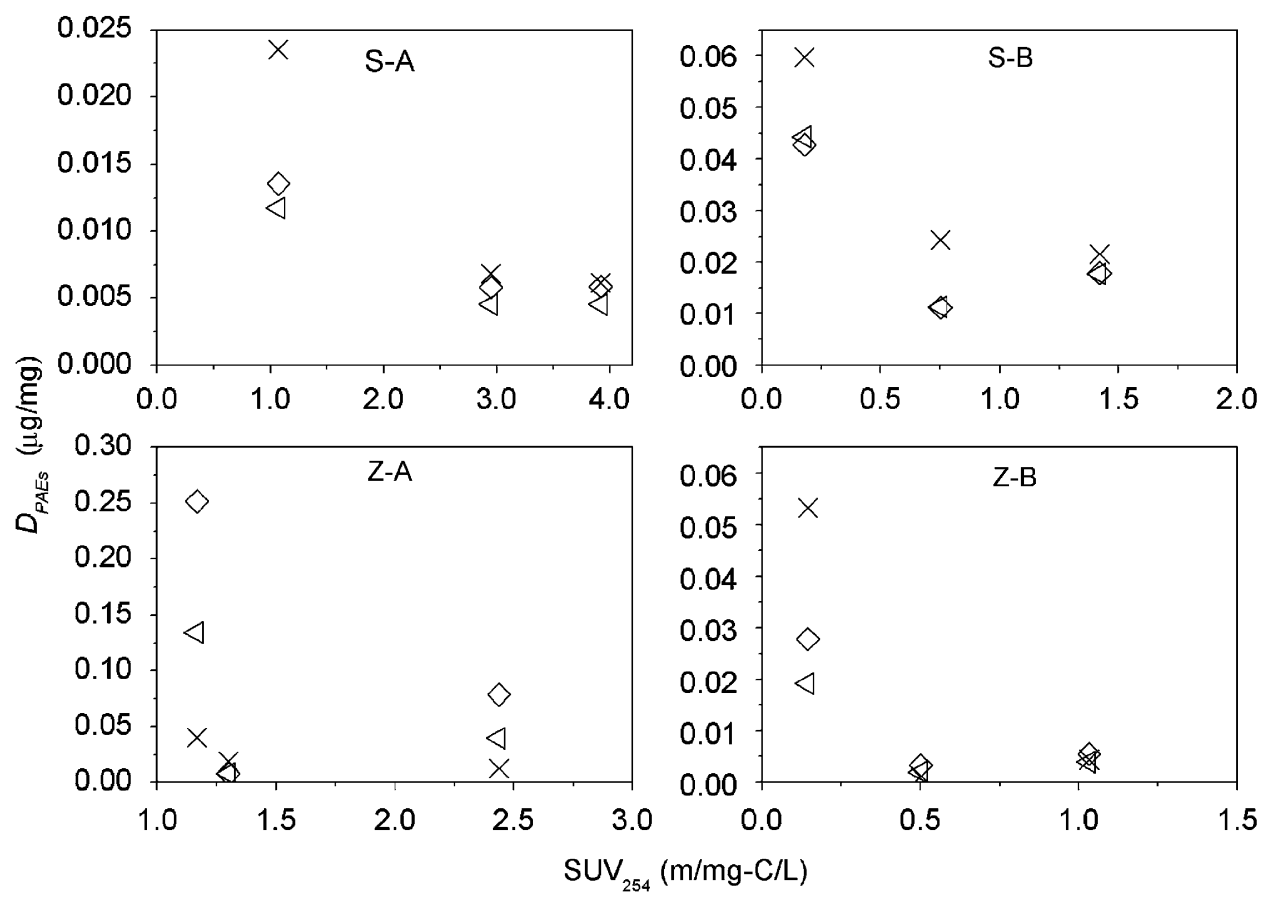

Fig. 4 - Change in the distribution of PAEs ( $\left.D_{\mathrm{PAEs}}, \mu \mathrm{g} / \mathrm{mg}\right)$ as a function of $\mathrm{SUVA}_{254}(\mathrm{~m} / \mathrm{mg} \mathrm{C} / \mathrm{L})$ of the landfill leachate DOM fractions for DIBP $(\square)$, DnBP $(\triangleleft)$ and DEHP $(x)$.

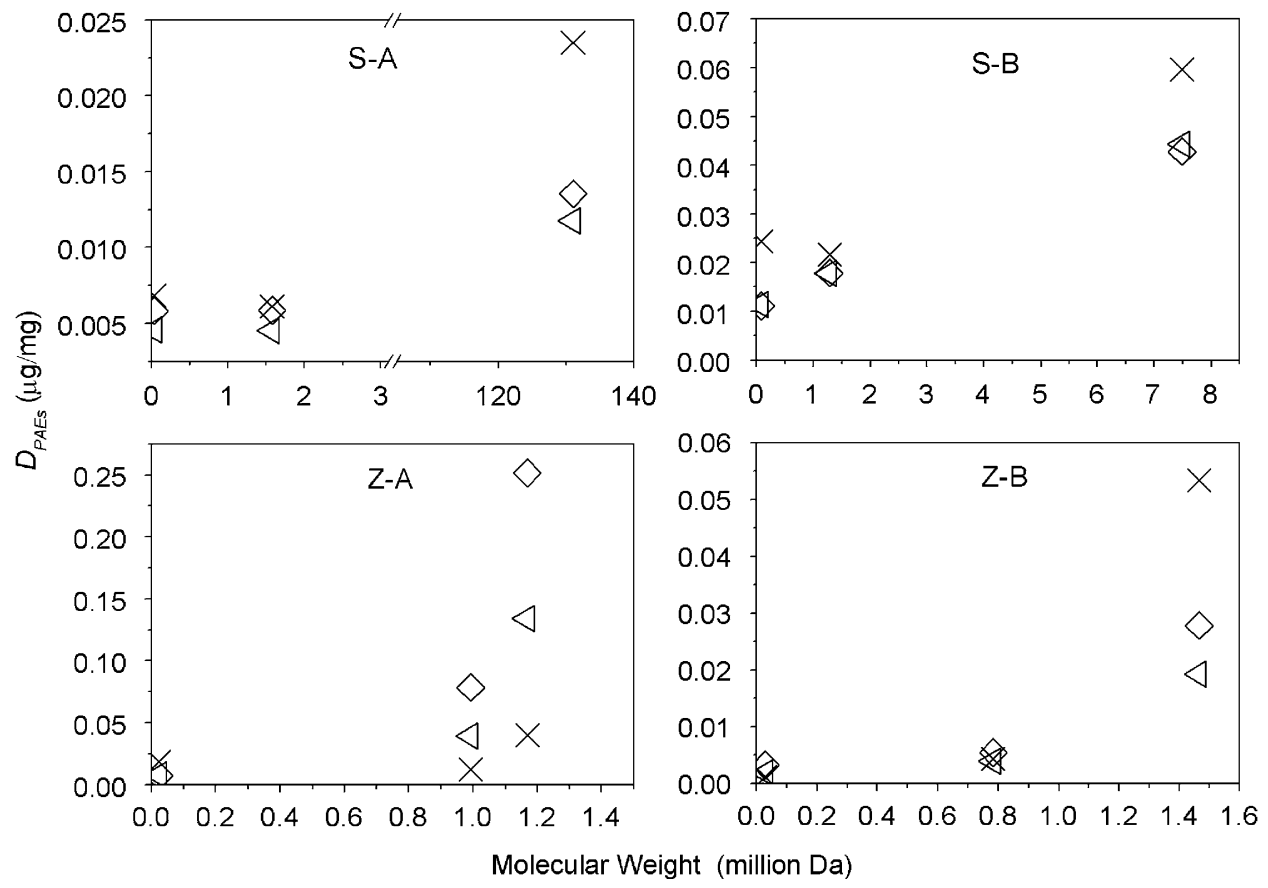

Fig. 5 - Change in the distribution of PAEs $\left(D_{\text {PAEs }} \mu \mathrm{g} / \mathrm{mg}\right)$ as a function of weight-average molecular weight (million $\left.\mathrm{Da}\right)$ of the landfill leachate DOM fractions for $\operatorname{DIBP}(\diamond), \operatorname{DnBP}(\triangleleft)$ and DEHP $(x)$.

2003). The presented IR spectra (Fig. 1) indicate that DOM fractions contain $\mathrm{H}$-donor groups: the phenolic and carboxyl or amide groups. Two hydrogen-bonding acceptors exist on PAE molecules. Hydrogen bonding may thus be involved in interactions between PAEs and leachate DOM. Schulten et al. (2001) theoretically identified the dominating intermolecular forces in sorption of diethylphthalate (DEP) on HA as hydrogen bonding and dipole-dipole interaction. However, since the presence of -NH-CO- groups (bands at 1546 and $1646 \mathrm{~cm}^{-1}$ in Fig. 1) is indicated in HA but not in the FA fraction of the leachate, the interactions between the peptide bonds and PAEs may be responsible for the higher $D_{\text {PAEs }}$ of the 

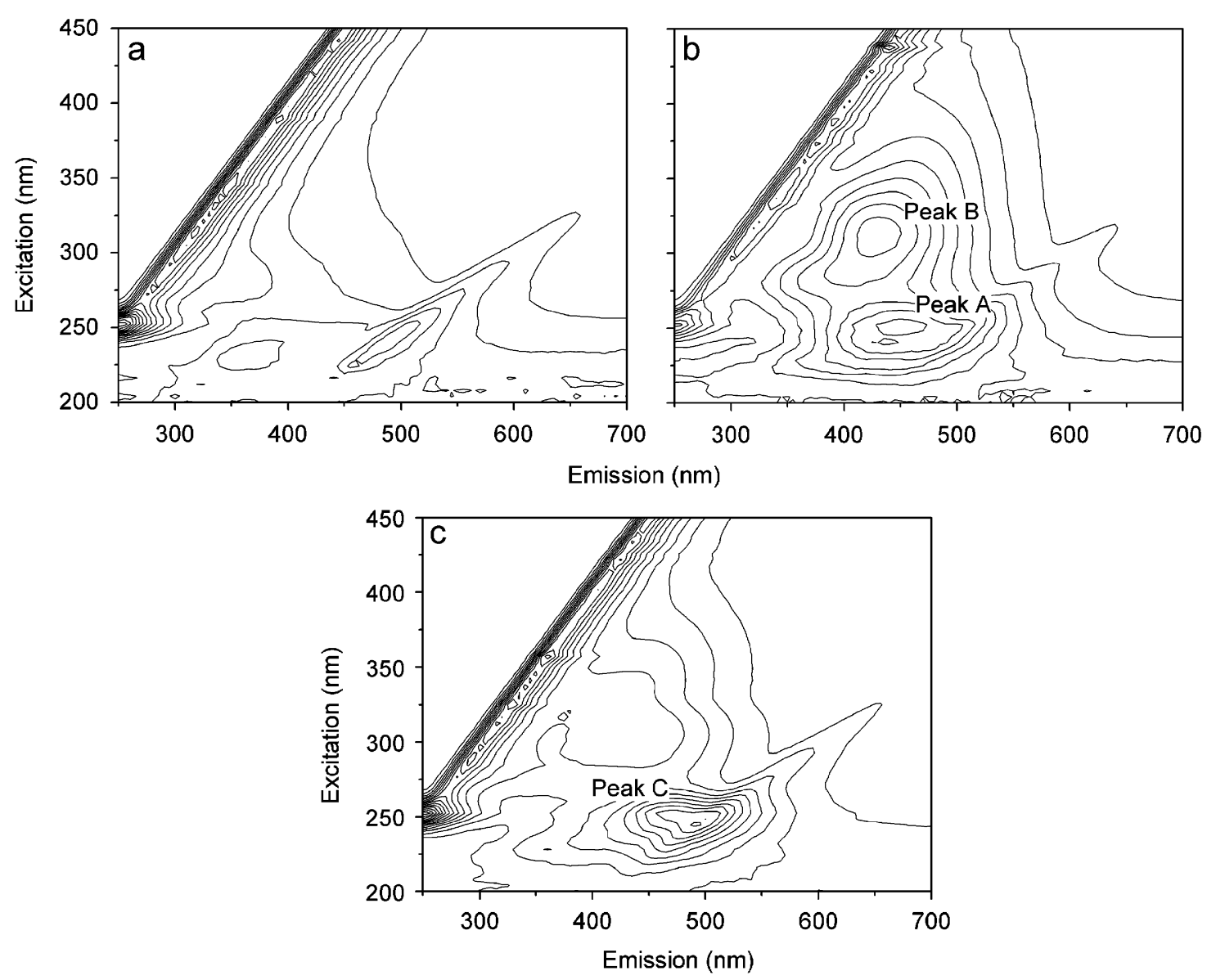

Fig. 6 - Fluorescene excitation-emission matrix spectra of FA (a) and HyI (b) in leachate Z-B.

HA. Many PAE molecules are readily adsorbed on HA molecules with high MW, which contain numerous peptide bonds.

The role of the HyI fraction in leachate on HOC adsorption has been largely ignored in the related literature, although, as detailed in Table 2, the HyI fraction accounted for $39-58 \%$ of the DOC in the landfill leachates. Consequently, the PAEs bound in the HyI fraction of leachate should not be ignored. Its SUVA $_{254}$ or $\mathrm{MW}$ is markedly lower than $\mathrm{HA}$ and FA fractions, indicating no correlation between the $\mathrm{SUVA}_{254}$ or MW with the high PAE adsorption capability of the HyI fraction.

The EEM contour plots of collected HA fractions in landfill leachate contained few aromatic groups (Fig. 6a). On the other hand, the collected FA samples generally displayed two distinct fluorophores at 250/445 nm (peak A) and 315/445 nm (peak B) (Fig. 6b), resembling those for HA and FA fingerprints (Lumsdon and Fraser, 2005). The red shift of peak A also corresponds to the increased humification of the FA molecules (Her et al., 2003).

The EEM contour plot of HyI (Fig. 6c) also revealed fluorophores at $250-255 / 465-475 \mathrm{~nm}$ (peak C) of humic characteristics. Thus, the HyI fractions shared certain similarities with humic substances in terms of molecular structure. These shared properties may be one reason why PAEs exhibit clear sorption on HyI fractions.

\subsection{Distributions and fates of PAEs}

The sorption characteristics of PAEs with different fractions of leachate could significantly influence their fate in and after leaving the landfill. It was well known that as the landfill age increases, molecular size and content of humic substances in leachate also tend to increase (Kang et al., 2002) and consequently the ratio of HA and FA changes (Chistensen et al., 1998). The potentials for PAE release from landfill thus increases with landfill age. The reduction in leachate recirculation thus reduced $\mathrm{HA}$ in leachate, and may limit PAE migration. Furthermore, since the treatment process, such as coagulation-sedimentation and electrolysis (He et al., 2006), could effectively remove HA fractions, it is a good candidate for removing PAEs in leachates.

\section{Conclusion}

This study showed that of the three fractions investigated (HA, FA and HyI), PAEs were mostly bound to the HA fraction, regardless of landfill age or leachate recirculation. The difference of PAE affinity for HA and FA was considerable relative to the sorption coefficients reported for model compounds. 
The results of this study indicate that the aromaticity of the DOM fractions is negatively correlated with the PAE affinity. Considering the molecular structure of PAEs and DOM fractions, it was suggested that the interactions between PAEs and leachate DOM is by hydrogen bonding. PAEs also exhibit clear sorption to DOM of the HyI fractions, which could be explained by the similarity of the HyI molecular structure to humic substances.

Because of the strong affinity of PAEs for the HA fractions of leachate, there is a clear potential that the migration of PAE has a close association with HA's fate in landfill or leachate treatment processes.

\section{Acknowledgments}

The authors acknowledge the financial support given by the General and Key Programs of the National Natural Science Foundation of China (NSFC) (50578115 and 50538080) and HiTech Research and Development Program of China (HTRDP) (2001AA644010 and 2003AA644020).

\section{R E F E R E N C E S}

Akkanen, J., Tuikka, A., Kukkonen, J.V.K., 2005. Comparative sorption and desorption of benzo[a]pyrene and 3,4,3', $4^{\prime}$-tetrachlorobiphenyl in natural lake water containing dissolved organic matter. Environ. Sci. Technol. 39 (19), 7529-7534.

Bauer, M.J., Herrman, R., 1997. Estimation of the environmental contamination by phthalic acid esters leaching from household wastes. Sci. Total Environ. 208 (1), 49-57.

Chistensen, J.B., Jensen, D.L., Grøn, C., Filip, Z., Christensen, T.H., 1998. Characterization of the dissolved organic carbon in landfill leachate-polluted groundwater. Water Res. 32 (1), 125-135.

Coors, A., Jones, P.D., Giesy, J.P., Ratte, H.T., 2003. Removal of estrogenic activity from municipal waste landfill leachate assessed with a bioassay based on reporter gene expression. Environ. Sci. Technol. 37 (15), 3430-3434.

Gigliotti, G., Onofri, A., Pannacci, E., Businelli, D., Marco, T., 2005. Influence of dissolved organic matter from waste material on the phytotoxicity and environmental fate of triflusulfuron methyl. Environ. Sci. Technol. 39 (19), 7446-7451.

He, P.J., Xue, J.F., Shao, L.M., Li, G.J., Lee, D.J., 2006. Dissolved organic matter (DOM) in recycled leachate of bioreactor landfill. Water Res. 40 (7), 1465-1473.

Her, N., Amy, G., McKnight, D., Sohn, J., Yoon, Y., 2003. Characterization of DOM as a function of mw by fluorescence EEM and HPLC-SEC using UVA, DOC and fluorescence detection. Water Res. 37 (17), 4295-4303.

Kang, K.H., Shin, H.S., Park, H., 2002. Characterization of humic substances present in landfill leachates with different landfill ages and its implications. Water Res. 36 (16), 4023-4032.
Kulshrestha, P., Giese, R.F.J., Aga, D.S., 2004. Investigating the molecular interactions of oxytetracycline in clay and organic matter: insights on factors affecting its mobility in soil. Environ. Sci. Technol. 38 (15), 4097-4105.

Li, C.W., Korshin, G.V., Benjamin, M.M., 1998. Monitoring DBP formation with differential UV spectroscopy. J. Am. Water Work Assoc. 90 (8), 88-100.

Lumsdon, D.G., Fraser, A.R., 2005. Infrared spectroscopic evidence supporting heterogeneous site binding models for humic substances. Environ. Sci. Technol. 39 (17), 6624-6631.

Ma, H., Allen, H.E., Yin, Y., 2001. Characterization of isolated fractions of dissolved organic matter from natural waters and a wastewater effluent. Water Res. 35 (4), 985-996.

Mackintosh, C.E., Maldonado, J.A., Ikonomou, M.G., Gobas, F.A.P.C., 2006. Sorption of phthalate esters and PCBs in a marine ecosystem. Environ. Sci. Technol. 40 (11), 3481-3488.

Müller, M.B., Fritz, W., Lankes, U., Frimmel, F.H., 2004. Ultrafiltration of nonionic surfactants and dissolved organic matter. Environ. Sci. Technol. 38 (4), 1124-1132.

Nascimento Filho, I., Mühlen, C.V., Schossler, P., Caramão, E.B., 2003. Identification of some plasticizers compounds in landfill leachate. Chemosphere 50 (5), 657-663.

Öman, C., Rosqvist, H., 1999. Transport fate of organic compounds with water through landfills. Water Res. 33 (10), 2247-2254.

Pedersen, J.A., Gabelich, C.J., Lin, C.-H., Suffet, I.H., 1999. Aeration effects on the partitioning of a PCB to anoxic estuarine sediment pore water dissolved organic matter. Environ. Sci. Technol. 33 (9), 1388-1397.

Perminova, I.V., Grechishcheva, N.Y., Petrosyan, V.S., 1999. Relationships between structure and binding affinity of humic substances for polycyclic aromatic hydrocarbons: relevance of molecular descriptors. Environ. Sci. Technol. 33 (21), 3781-3787.

Polak, J., Sułkowski, W.W., Bartoszek, M., Papież, W., 2005. Spectroscopic studies of the progress of humification processes in humic acid extracted from sewage sludge. J. Mol. Struct. 744, 983-989.

Schulten, H.-R., Thomsen, M., Carlsen, L., 2001. Humic complexes of diethyl phthalate: molecular modelling of the sorption process. Chemosphere 45 (3), 357-369.

Schwarzbauer, J., Heim, S., Brinker, S., Littke, R., 2002. Occurrence and alteration of organic contaminants in seepage and leakage water from a waste deposit landfill. Water Res. 36 (9), 2275-2287.

Vilomet, J.D., Veron, A., Ambrosi, J.P., Moustier, S., ChateletSnidaro, L., 2003. Isotopic tracing of landfill leachates and pollutant lead mobility in soil and groundwater. Environ. Sci. Technol. 37 (20), 4586-4591.

Walse, S.S., Morgan, S.L., Kong, L., Ferry, J.L., 2004. Role of dissolved organic matter, nitrate, and bicarbonate in the photolysis of aqueous fipronil. Environ. Sci. Technol. 38 (14), 3908-3915.

Yamamoto, H., Liljestrand, H., Shimizu, Y., Morita, M., 2003. Effects of physical-chemical characteristics on the sorption of selected endocrine disruptors by dissolved organic matter surrogates. Environ. Sci. Technol. 37 (12), 2646-2657. 